Vol. 1 No. 2, Juni 2021, hlm. 167 - 172

DOI: https://doi.org/10.33330/jutsi.v2i1.1166

Available online at http://jurnal.stmikroyal.ac.id/index.php/jutsi

\title{
RANCANG BANGUN SISTEM PAKAR UNTUK PENANGANAN PENYAKIT PADA DURIAN BERBASIS WEB
}

\author{
Alfi Syahrinur Sitorus ${ }^{1}$, Juna Eska ${ }^{2}$, Sumantri ${ }^{3}$ \\ ${ }^{1}$ Mahasiswa Prodi Sistem Informasi, STMIK Royal \\ ${ }^{2}$ Prodi Sistem Komputer, STMIK Royal \\ ${ }^{3}$ Prodi Sistem Informasi, STMIK Royal \\ *email : dosen.junaeska@gmail.com
}

\begin{abstract}
In cultivating durian farmers often suffer losses because durian plants are always attacked by pests and durian plant diseases because farmers still use manual methods to find out in dealing with durian plant diseases. From the existing problems, the purpose of this study is to design an expert system with Certainty factor method in handling web-based durian plant diseases that can be accessed by anyone. The benefits of this research provide convenience and help farmers to consult those who have activities worthy of a very experienced system such as experts. The expert system method used is using Certainty factor. The research methodology used by using a qualitative approach. The location of this research was conducted at the Asahan District Agriculture Service specifically in the field of plantations. The design model uses the Rad model, the programming language used by PHP and MySQL as its database. The results of this study are expected by the application of an expert system using the web-based Certainty factor method to diagnose diseases in durian plants and provide treatment solutions so that it can make it easier for farmers and communities to deal with diseases in the durian plants.
\end{abstract}

Keywords: Expert System; Durian; Certainty factor

\begin{abstract}
Abstrak: Dalam membudidayakan durian petani selalu merasa rugi disebabkan tanaman durian selalu diserang para hama dan penyakit tanaman durian dikarenakan mereka tetap memakai cara yang kuno saat mendeteksi serta mengatasi penyakit tanaman durian. Dari permasalahan tersebut jadi tujuan penelitian ini agar merancang sistem pakar dengan metode Certainty factor pada penanganan penyakit tanaman durian berbasis web yang dapat diakses oleh siapa saja. Manfaat dari penelitian ini memberikan serta mempermudah juga menolong para petani ketika bertanya, juga mempunyai aktifitas seperti sistem yang handal bagaikan para ahli. Metode sistem pakar yang digunakan menggunkan Certainty factor. Metodeologi penelitian yang dipakai dengan menggunakan kualitatif. Tempat penelitian ini berada pada Dinas Pertanian kabupaten Asahan khusus nya dibidang perkebunan. Model perancangan menggunakan model Rad, bahasa pemograman yang dipakai php dan MySQL menjadi penyimpanan data nya. Hasil akhir dari penelitian ini diharapkan dengan adanya aplikasi sistem pakar memakai cara Certainty factor berjalan di web dapat mendiagnosa penyakit pada tanaman durian dan memberikan solusi penanganannya sehingga dapat lebih memudahkan petani dan masyarakat dalam menangani penyakit pada tanaman durian tersebut.
\end{abstract}

Kata Kunci : Sistem Pakar; Durian; Certainty Factor 
Vol. 1 No. 2, Juni 2021, hlm. 167 - 172

DOI: https://doi.org/10.33330/jutsi.v2i1.1166

Available online at http://jurnal.stmikroyal.ac.id/index.php/jutsi

\section{PENDAHULUAN}

Dengan berjalan waktu dan kian bertambahnya pengetahuan, teknologi komputer juga mengalami kemajuan yang pesat. Dapat terlihat bersama perkembangan teknologi yang bisa mengambil peran dan teknik pola pikir manusia yang dinamakan sebagai artificial intelligence atau sering disebut sistem pakar. Sistem pakar bisa dalam mengambil sebuah teknik awal pengetahuan (knowledge base) yang di proleh dari data yang dimasukkan berdasarkan ilmu para pakar di sebuah bidang yang sifatnya detail [1] . Sistem pakar ialah sebuah sistem yang di bangun agar bisa mencontoh kemampuan seorang pakar saat menjawab pertanyaan juga menemukan penyelesaian masalah tersebut [2]. Sistem pakar juga mengedepankan penyelesaian sebuah masalah yang di dapat dari perckapan dengan pengguna. Dengan adanya sistem pakar orang yang tidak pakar bisa menangani masalah juga memutuskan tindakan seperti seorang pakar.

Dinas pertanian adalah salah satu instansi pemerintahan yang bertugas membantu bupati melaksanakan urusan pemerintah dibidang pertanian yang menjadi kewenangan daerah. Dinas pertanian berkendudukan dan bertanggung jawab kepada bupati melalui sekretaris daerah.

Durian merupakan salah satu varietas buah yang ada di Indonesia, Indonesia merupakan negara tropis yang kaya akan buah-buahan. Dari sekian banyaknya varietas buah-buahan yang berkembang di Indonesia, tentunya tidak semua dapat diunggulkan. The king of the fruit, merupakan julukan bagi buah durian yang merupakan salah satu jenis buah yang telah lama berkembang dan ditanam di wilayah nusantara ini [3] . Daging buahnya yang bertekstur lunak dengan rasa yang nikmat serta baunya yang khas dan tajam membuat buah yang berduri ini selalu digemari oleh berbagai lapisan masyarakat walaupun harganya relatif mahal. Bobot total buah durian terdiri dari tiga bagian. Bagian pertama, daging buah sekitar 20-35\%; kedua, biji sekitar 5-15\%; sisanya berupa bobot kulit yang mencapai $60-75 \%$ dari bobot total buah. Pohon durian yang untuk ditanam dilahan yang miring karena tidak tahan terhadap air, pohon durian mempunyai umur produktif yang panjang (lebih dari 100 tahun), sehingga merupakan jenis flora penjaga lingkungan yang efektif dalam jangka panjang. Manfaat ini semakin memperkuat posisi durian lebih unggul dengan jenis tanaman yang lain. Habitat tumbuh durian seperti daerah yang lembab, ukuran pohonnya bisa mencapai tinggi 30-40 m dengan diameter batang melebihi 2,5 $\mathrm{m}$. Durian yang berasal dari bibit sambung/grafting ukuran pohonnya lebih rendah yaitu sekitar $12 \mathrm{~m}$.

Sekarang ini, petani sudah sadar jika mengembangkan durian itu sangat berpeluang besar atau bisa menghasilkan pendapatan yang lumayan besar. Itu bisa terjadi apabila tanaman durian dikembangkan menggunkan cara yang tepat, jadi ketentuan dasar supaya menghasilkan laba banyak, saat mengembangkan durian terdapat di perawatannya. saat ini, petani selalu merasa rugi disebabkan tanaman durian selalu diserbu hama dan penyakit tanaman durian. Hal itu terjadi dikarnakan para petani masih menggunakan cara yang manual untuk mengetahui tentang hama dan penyakit serta penanganan pada tanaman durian. Dan untuk lebih jelas mengetahui penyakit serta penanganan durian tersebut, para petani harus 
Vol. 1 No. 2, Juni 2021, hlm. 167 - 172

DOI: https://doi.org/10.33330/jutsi.v2i1.1166

Available online at http://jurnal.stmikroyal.ac.id/index.php/jutsi

menunggu tim penyuluh dari dinas pertanian datang kekebun mereka, Masalah hama dan penyakit tanaman durian ialah masalah selalu dialami petani. Minimnya ilmu ketika mendiagnosa hama dan penyakit tanaman durian dan seperti apa mengambil tindakan yang pas mengatasi gejala.Hal tersebut yang mengkhawatirkan para petugas Dinas Pertanian Kabupaten Asa-han yang beralamat jalan Jendral Gatot Subroto No. 268, Sentang, Kisaran, Kedai Ledang, Kec. Kisaran Timur Kab. Asahan. Karena hal tersebut menyebabkan semakin sedikitnya produksi buah durian. Untuk menjaga agar produksi durian tidak mengalami penurunan, maka dibutuhkan suatu rancangan.

\section{METODE}

Metode yang dipakai dalam diagnosa penyakit pada tanaman durian adalah teknik certainty factor. Certainty Factor merupakan sebuah teknik agar membuktikan akan sebuah kebenaran itu pasti ataukah tidak yang beentuknya metric yang selalu dipakai di sistem pakar. Certainty Factor juga dapat diartikan yaitu metode untuk mendapatkan suatu kepastian dari suatu data [4]. cara ini begitu pas ke sistem pakar yang menentukan pasti ataupun belum ril. Tahapan dalam merepresentasikan data-data kualitatif : (1) Kelebihannya bisa mengekspresikan derajat keyakinan sesuai dengan metode., (2) Keahlian dalam meletakkan juga mengkolaborasikan tingkat kepercayaan tersebut ke sistem pakar. ketika menunjukkan tingkat kepercayaan dipakai sebuah nilai disebut Certainy Factor. Agar menyimpulkan tingkat kepercayaan pakar pada sebuah data. Ini merupakan formula tentang dari Certainy Factor :

$$
\mathrm{CF}[\mathrm{H.E}]=\mathrm{MB}[\mathrm{H}, \mathrm{E}]-\mathrm{MD}[\mathrm{H}, \mathrm{E}]
$$

Penjelasan :

$\mathrm{CF}$ :Faktor Kepastian dalam jawaban sementara $\mathrm{H}$ berdasarkan oleh fakta $\mathrm{E}$.

MB :Tingkat kepercayaan, merupakan landasan naik sebuah keyakinan jawaban sementara $\mathrm{H}$ berdasarkan oleh kebenaran $\mathrm{E}$.

MD :Tingkat ketidak percayaan, ialah naiknya sebuah ketidak yakinan jawaban sementara $\mathrm{H}$ berdasarkan kebenaran $\mathrm{E}$.

E : Peristiwa atau kebenaran

$\mathrm{H}$ : Jawaban sementara [5].

Dalam mengombinasikan 2 atau lebih aturan, sistem berdarkan informasi menjadi beberapa aturan, setiap darinya mendapatkan simpulan sama tapi penyebab tidak pastiannya lain, maka setiap rule bisa ditunjukkan menjadi gambaran bukti yang mendukung simpulan bersama. dalam mencari $\mathrm{CF}$ dari kesimpulan membutuhkan bukti pengkolaborasian seperti ini :

$$
\mathrm{CF}(\mathrm{R} 1, \mathrm{R} 2)=\mathrm{CF}(\mathrm{R} 1)+[\mathrm{CF}(\mathrm{R} 2)] \times[1-\mathrm{CF}(\mathrm{R} 1)]
$$


Vol. 1 No. 2, Juni 2021, hlm. $167-172$

DOI: https://doi.org/10.33330/jutsi.v2i1.1166

Available online at http://jurnal.stmikroyal.ac.id/index.php/jutsi

Kalau kita hanya menambahkan (Certainty Factor) CF R1 dan R2, kebenaran kolaborasi menjadi lebih dari 1. Merubah jumlah kepastian dari penambahan dengan factor kebenaran kedua dan mengalikannya (1 dikurangi faktor kepastian pertama). Jadi, semakin besar CF (Certainty Factor) pertama menjadi kecil kebenaran penambahan kedua. Tapi penyebab tambahan sering menambahkan beberapa kepastian.

\section{HASIL DAN PEMBAHASAN}

Hasil dan pembahasan penelitin ini seperti tampak pada gambar berikut :

\section{Halaman Penyakit}

Halaman penyakit merupakan halaman untuk menampilkan penyakit menambahkan penyakit, menghapus, dan mengeditnya. Berikut ini adalah tampilan halaman penyakit pada gambar 1.

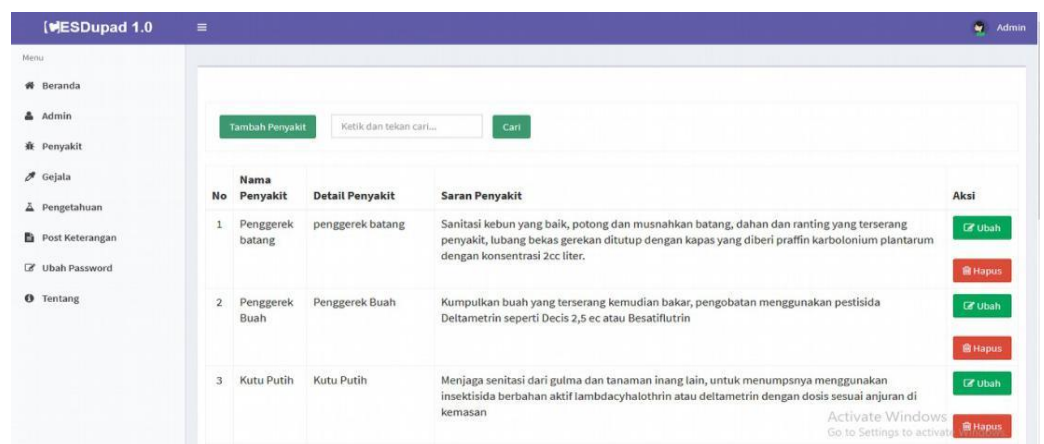

Gambar 1. Tampilan Halaman Diagnosa Penyakit

\section{Halaman Gejala}

Halaman gejala menampilkan gejala-gejala yang ada pada diagnosa, halaman ini merupakan halaman untuk menambah, mengedit, dan menghapus gejala. Berikut ini adalah halaman gejala pada gambar 2 .

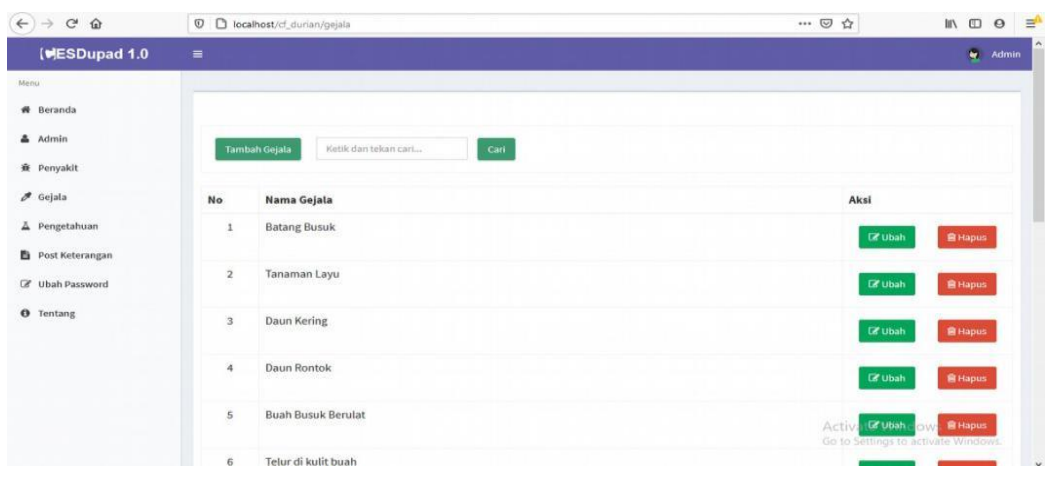

Gambar 2. Tampilan Halaman Gejala 
Vol. 1 No. 2, Juni 2021, hlm. 167 - 172

DOI: https://doi.org/10.33330/jutsi.v2i1.1166

Available online at http://jurnal.stmikroyal.ac.id/index.php/jutsi

\section{Halaman Pengetahuan}

Halaman Pengetahuan berisi tentang relasi penyakit dan gejala. Berikut ini adalah Halaman Pengetahuan pada gambar 3.

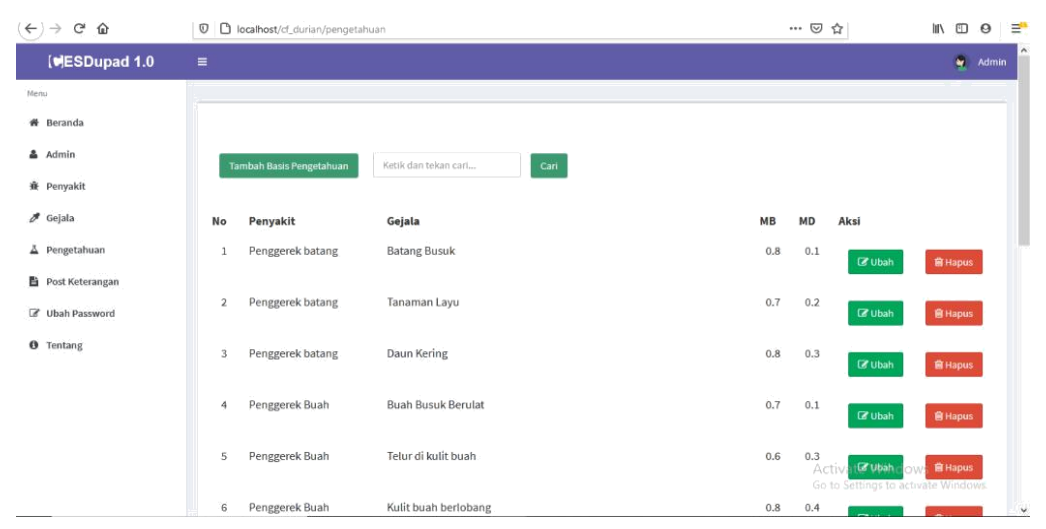

Gambar 3. Tampilan Halaman Pengetahuan

\section{Halaman Diagnosa}

Halaman Diagnosa merupakan halaman dimana (user) pengguna dapat berkonsultasi tentang gejala yang dialami durian, berikut ini adalah halaman Diagnosa pada gambar 4.

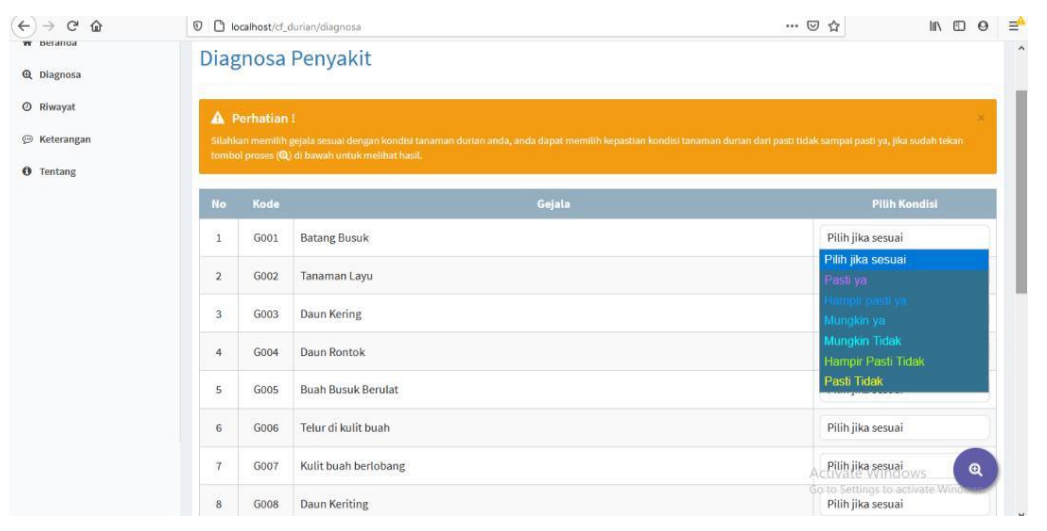

Gambar 4. Tampilan Halaman Diagnosa

\section{Halaman Hasil Diagnosa}

Halaman hasil diagnosa merupakan halaman yang menampilkan hasil diagnosa dari konsultasi user ke program. Berikut ini adalah halaman hasil diagnosa pada gambar 5. 
Vol. 1 No. 2, Juni 2021, hlm. 167 - 172

DOI: https://doi.org/10.33330/jutsi.v2i1.1166

Available online at http://jurnal.stmikroyal.ac.id/index.php/jutsi

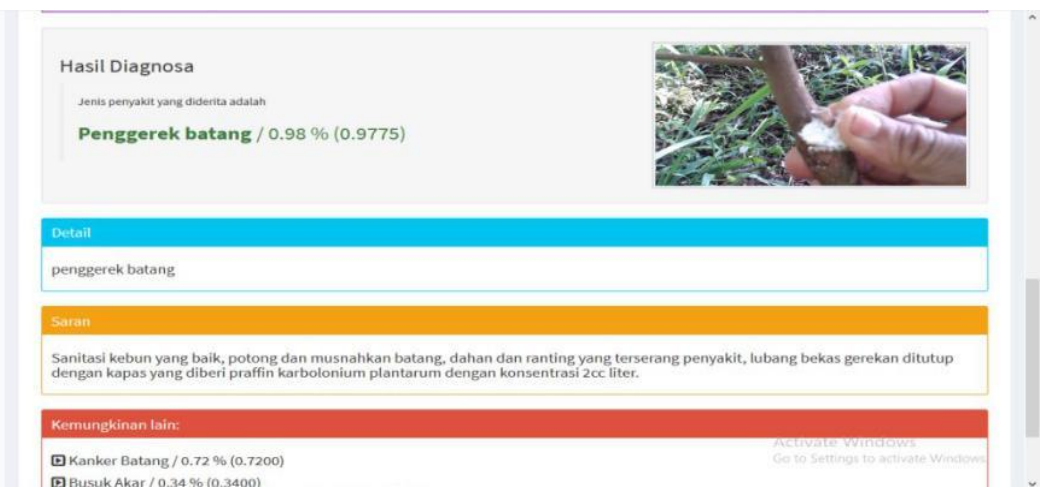

Gambar 5. Tampilan hasil diagnosa

\section{SIMPULAN}

Dari hasil penelitian yang berjudul Rancang bangun Sistem Pakar Penanganan penyakit pada durian dengan Metode Certainty Factor Pada Dinas Pertanian kabupaten asahan, peneliti dapat mengambil beberapa kesimpulan antara lain sebagai berikut: (1) Dengan adanya sistem pakar berbasis web tentang penyakit dan penanganan durian, petani lebih mudah mengetahui penyakit yang sedang terjadi pada tanamannya, serta mengetahui penanganannya., (2) Dengan adanya website ini dapat memperluas pembudidayaan tanaman durian. Petani dan masyarakat akan lebih mudah mendapatkan informasi tentang seputar tanaman durian dengan mengakses website ini.

\section{DAFTAR PUSTAKA}

[1] S. Indah, A. Calam, B. Andika, and S. A. Kartini, "Sistem Pakar Untuk Mendeteksi Bibit Durian Unggul Pada," vol. 17, no. 1, pp. 64-73, 2018.

[2] A. F. Rohman, Feri Fahrur, "Feri Fahrur Rohman," Ranc. Bangun Apl. Sist. Pakar Untuk Menentukan Jenis Gangguan Perkemb. Pada Anak, Vol. 6, No. 1, Pp. 1-23, 2008, Doi: 10.1164/Rccm.2312011.

[3] A. Furqon and N. I. Fadlilah, "Sistem Pakar Untuk Mendiagnosa Hama Dan Penyakit Pada Pohon Durian," Konf. Nas. Ilmu Sos. Teknol., pp. 105-109, 2016.

[4] Z. Arief, "Rancang bangun aplikasi mobile untuk mendiagnosis penyakit pada tanaman melon menggunakan Metode Certainty Factor," JATI (Jurnal Mhs. Tek. Inform., vol. 2, no. 1, pp. 92-99, 2018, [Online]. Available: https://ejournal.itn.ac.id/index.php/jati/article/view/1248.

[5] D. C. Rezza Ramadhan, Indah Fitri Astuti, "Sistem Pakar Diagnosis Penyakit Kulit Pada Kucing Menggunakan Metode Certainty Factor David," J. Sist. Inf. Situs, vol. 3, no. 1, 2014. 